\title{
Artemisinin induced reversal of EMT affects the molecular biological activity of ovarian cancer SKOV3 cell lines
}

\author{
WEICHEN LIANG $^{1 *}$, JIAN LIU $^{1 *}$, HUAZHANG WU ${ }^{2}$, XUXU QIAO ${ }^{3}$, \\ XIANG LU ${ }^{1}$, YONGHONG LIU ${ }^{3}$, HONG ZHU ${ }^{1}$ and LING MA ${ }^{1}$ \\ ${ }^{1}$ Department of Gynecologic Oncology, First Affiliated Hospital of Bengbu Medical College; \\ ${ }^{2}$ Anhui Province Key Laboratory of Tissue Transplantation, Bengbu Medical College; ${ }^{3}$ Graduate Department, \\ Bengbu Medical College, Bengbu, Anhui 233030, P.R. China
}

Received October 18, 2018; Accepted June 13, 2019

DOI: $10.3892 / \mathrm{ol} .2019 .10608$

\begin{abstract}
Accumulating evidence suggests that celecoxib and artemisinin could mediate ovarian cancer development and metastasis. The present study investigated the effects of celecoxib and artemisinin on the epithelial-mesenchymal transition (EMT) characteristics of the human ovarian epithelial adenocarcinoma cell line, SKOV3. SKOV3 cells were incubated with celecoxib $(10 \mu \mathrm{M})$ for different periods of time to establish an EMT cell model. Subsequently, artemisinin (20, 40 and $80 \mu \mathrm{M}$ ) was used to establish a cell model of the reverse process, mesenchymal-epithelial transition (MET). Cell proliferation, metastasis, invasiveness and the expression of vimentin and E-cadherin were measured using Cell Counting Kit-8, wound healing assay, western blotting, flow cytometry and immunofluorescence. The EMT cell model exhibited enhanced proliferative capacity, increased migration, increased vimentin expression and decreased E-cadherin expression. By contrast, artemisinin decreased proliferative capacity, decreased migration, decreased vimentin expression and increased E-cadherin expression of EMT model cells, indicating that MET was induced. These results demonstrated that artemisinin may reverse celecoxib-induced epithelial-mesenchymal transition in SKOV3 cells.
\end{abstract}

\section{Introduction}

Ovarian cancer has the highest mortality of reproductive system tumors; most patients have already progressed to a late stage when diagnosed due to the high invasiveness and

Correspondence to: Dr Ling Ma, Department of Gynecologic Oncology, First Affiliated Hospital of Bengbu Medical College, 287 Changhuai Road, Bengbu, Anhui 233030, P.R. China E-mail:m11970222@163.com

*Contributed equally

Key words: epithelial-mesenchymal transition, ovarian cancer, artemisinin, celecoxib, SKOV3 cell line recurrence of ovarian tumors (1-4). Epithelial-mesenchymal transition (EMT) is the biological process during which epithelial cells acquire abnormal motor forces due to specific environmental changes or pathological factors, and transform from an epithelial phenotype to an interstitial phenotype $(5,6)$. A previous study has demonstrated that $90 \%$ of ovarian cancers are epithelial and that EMT is associated with the metastasis and recurrence of malignant tumors (7). Therefore, understanding EMT is crucial for elucidating the mechanisms that induce ovarian cancer metastasis.

Celecoxib is a non-steroidal anti-inflammatory drug commonly used for the treatment of fever, pain, stiffness and swelling (8). Previous studies have confirmed that celecoxib regulates the cell cycle, promotes apoptosis, inhibits angiogenesis and induces EMT in epithelial cancers, such as lung cancer, thus affecting the development of tumors $(9,10)$. Artemisinin and its derivatives (collectively termed as artemisinins) are among the most important and effective antimalarial drugs. In addition to their antimalarial effects, artemisinins have also been demonstrated to possess selective anticancer properties. These effects appear to be mediated by artemisinin-induced changes in multiple signaling pathways, interfering simultaneously with multiple hallmarks of cancer (11). Artemisinin exhibits strong antitumor activity, although it is unclear whether artemisinin can reverse EMT $(11,12)$. In the present study, an EMT model of ovarian cancer cell line SKOV3 cells induced by celecoxib was established in vitro; subsequently, mesenchymal-epithelial transition (MET) was induced by artemisinin. The effects of artemisinin on molecular biological characteristics of the two models and EMT were analyzed. The present study has laid a foundation for the study of genes and signal transduction pathways that are affected by artemisinin during the development and progression of ovarian cancer and is of great clinical significance for future research of artemisinin as an anti-ovarian cancer drug.

\section{Materials and methods}

Cell culture. The human ovarian epithelial adenocarcinoma cell line SKOV3 was purchased from the Type Culture Collection of the Chinese Academy of Sciences.SKOV3 cells were cultured in RPMI 1640 medium (HyClone; GE Healthcare 
Life Sciences) containing 10\% FBS (Hangzhou Sijiqing Biological Engineering Materials Co., Ltd.), $50 \mu \mathrm{g} / \mathrm{ml}$ penicillin (HyClone; GE Healthcare Life Sciences), and $50 \mu \mathrm{g} / \mathrm{ml}$ streptomycin (HyClone; GE Healthcare Life Sciences) in a humidified atmosphere at $37^{\circ} \mathrm{C}$ and $5 \% \mathrm{CO}_{2}$, and the culture medium was changed every three days.

Establishment of cell models. SKOV3 cells were suspended and cultured in $2 \mathrm{ml}$ of culture medium at the final concentration of $5 \times 10^{5}$ cells $/ \mathrm{ml}$. After the cells were stably anchored overnight, the medium was discarded and $2 \mathrm{ml}$ complete medium containing $10 \mu \mathrm{M}$ celecoxib (Shanghai Macklin Biochemical Co., Ltd.) was added to the flask (10). Following incubation with celecoxib for $12,24,36,48$ or $72 \mathrm{~h}$ at $37^{\circ} \mathrm{C}$, an EMT model of SKOV3 cells was established. Untreated SKOV 3 cells were used as controls. The EMT cell model with 48-h incubation period (highest proliferation rate confirmed by cell viability assay) was selected as the 'control' EMT model for subsequent experiments. Cells (i.e. EMT model) were resuspended at a final concentration of $5 \times 10^{5}$ cells $/ \mathrm{ml}$ in $6 \mathrm{ml}$, of which $2 \mathrm{ml}$ were inoculated into a new flask resulting in a total of three flasks. The cells were incubated overnight, the culture medium was discarded and 20,40 and $80 \mu \mathrm{M}$ artemisinin (Melone Pharmaceutical Co., Ltd.) were added to the culture flask with a total volume of $2 \mathrm{ml}$. A MET cell model was established following 48-h incubation with artemisinin.

Cell viability assay. Cell viability was assessed using a Cell Counting Kit-8(CCK-8; Biosharp). Untreated SKOV3 control cells, cells treated with $10 \mu \mathrm{M}$ celecoxib for $48 \mathrm{~h}$ (EMT model) and further treated with 20,40 and $80 \mu \mathrm{M}$ artemisinin for $48 \mathrm{~h}$ (MET cell model) were harvested and resuspended at a final concentration of $5 \times 10^{3}$ cells $/ \mathrm{ml}$ and seeded into $96-$ well plates. Subsequently, $10 \mu \mathrm{l}$ CCK-8 solution was added to each well, and the plates were incubated at $37^{\circ} \mathrm{C}$ for $2 \mathrm{~h}$. Optical density (OD) values were measured at $450 \mathrm{~nm}$ using a microplate reader (Biotex, Inc.). Cell viability was calculated as follows: Cell viability $(\%)=(\mathrm{OD}$ of experimental group - OD of blank group) / (OD of control group-OD of blank group) x 100. The experiments were repeated at least five times.

Wound healing assay. Cells from all models were plated in 6 -well plates at a density of $5 \times 10^{5}$ cells/well. When cell confluence reached $90 \%$, vertical scratches were formed in the cell layer by using a $10 \mu \mathrm{l}$ pipette tip. Floating cells were removed by washing with PBS. Culture medium without FBS was added to the cells, and cells were incubated at $37^{\circ} \mathrm{C}$ with $5 \% \mathrm{CO}_{2}$ and saturated humidity for $48 \mathrm{~h}$. Cell migration was observed at 0 and $48 \mathrm{~h}$. The scratch-healing areas were calculated using ImageJ 1.8.0 (National Institutes of Health) and the following formula: Scratch-healing $(\%)=$ (initial scratch area-final scratch area) /initial scratch area $\mathrm{x} 100$. The experiments were repeated at least three times.

Protein extraction and western blot analysis. The flasks with cells were washed three times with ice cold PBS and total protein was harvested in RIPA lysis buffer (Beyotime Institute of Biotechnology) containing PMSF (1:100). A bicinchoninic acid protein assay kit (Beyotime Institute of Biotechnology) was used to determine protein concentrations. Proteins (30 $\mu \mathrm{g})$ were separated by SDS-PAGE on $10 \%$ gels and transferred to a PVDF membrane (Beyotime Institute of Biotechnology). The membranes were blocked with $5 \%$ skimmed milk in TBS containing Tween-20 (TBST) for $1 \mathrm{~h}$ at $37^{\circ} \mathrm{C}$ and incubated with primary antibodies against vimentin (polyclonal; cat. no. ABP52699; 1:1,000; Abbkine Scientific Co., Ltd.) and E-cadherin (polyclonal; cat. no. ABP51221; 1:1,000; Abbkine Scientific Co., Ltd.) overnight at $4^{\circ} \mathrm{C}$. Following washing three times with TBST, the membrane was incubated with horseradish peroxidase-conjugated goat anti-rabbit IgG antibody (cat. no. BL003A; 1:8,000; Biosharp; Beijing Lanjieke Technology Co., Ltd.) at $37^{\circ} \mathrm{C}$ for $1 \mathrm{~h}$. E-cadherin and vimentin were visualized using an electrochemiluminescence chromogenic kit (Beyotime Institute of Biotechnology) in a dark room. Densitometry was performed using ImageJ 1.8.0. The experiments were repeated at least three times.

Flow cytometric analysis. SKOV3 cells were plated in 6-well plates at a density of $5 \times 10^{5}$ cells/well and allowed to attach overnight prior to treatment (i.e. induction into EMT and MET models). Cells were harvested, fixed with $4 \%$ paraformaldehyde (Sigma-Aldrich; Merck KGaA) for $30 \mathrm{~min}$ at $25^{\circ} \mathrm{C}$, and permeabilized with $0.1 \%$ Triton X-100 (Sigma-Aldrich; Merck $\mathrm{KGaA}$ ) in PBS for $20 \mathrm{~min}$ at room temperature. The cells were blocked with 5\% goat serum (Hangzhou Sijiqing Biological Engineering Materials Co., Ltd.) and 0.3\% Triton X-100 in PBS for $30 \mathrm{~min}$ at $37^{\circ} \mathrm{C}$, incubated with the primary antibodies against vimentin and E-cadherin (polyclonal; 1:1,000; AbbkineScientific Co., Ltd.) for $30 \mathrm{~min}$ at $37^{\circ} \mathrm{C}$ and further incubated with FITC-labeled goat anti-rabbit IgG (cat. no. BL033A; 1:50; Biosharp; Beijing Lanjieke Technology Co., Ltd.) for $30 \mathrm{~min}$ at $37^{\circ} \mathrm{C}$. Labeled cells were detected using a Cytomics FC 500 flow cytometer (BD Biosciences). The average fluorescence intensity was analyzed using FlowJo 7.6 software (BD Biosciences). The experiments were repeated at least three times.

Immunofluorescence staining and confocal imaging. SKOV3 cells were plated onto coverslips in 6-well plates at a density of $1 \times 10^{5}$ cells/well and allowed to attach overnight prior to treatment. The coverslips were fixed with $4 \%$ paraformaldehyde for $30 \mathrm{~min}$ at room temperature and permeabilized with $0.1 \%$ Triton $\mathrm{X}-100$ in PBS at room temperature for $20 \mathrm{~min}$. The coverslips were blocked in 5\% goat serum and $0.3 \%$ Triton X-100 in PBS at $37^{\circ} \mathrm{C}$ for $30 \mathrm{~min}$, incubated with the primary antibodies against vimentin (polyclonal; cat. no. ABP52699; 1:1,000; AbbkineScientific Co., Ltd.) and E-cadherin (polyclonal; cat. no. ABP51221; 1:1,000; Abbkine Scientific Co., Ltd.) at $37^{\circ} \mathrm{C}$ for $30 \mathrm{~min}$ and further incubated with FITC-labeled goat anti-rabbit IgG (cat. no. BL033A; 1:50; Biosharp; Beijing Lanjieke Technology Co., Ltd.) at $37^{\circ} \mathrm{C}$ for $30 \mathrm{~min}$. DAPI (Beyotime Institute of Biotechnology) was added to the coverslips and incubated in the dark at room temperature for $10 \mathrm{~min}$. The coverslips were washed with PBS and mounted onto slides with glycerol:water (1:1). An Olympus FV-1200MPE SHARE confocal microscope (Olympus Corporation) was used to visualize the cells. Images were processed and quantified using ImageJ. The experiments were repeated at least three times. 

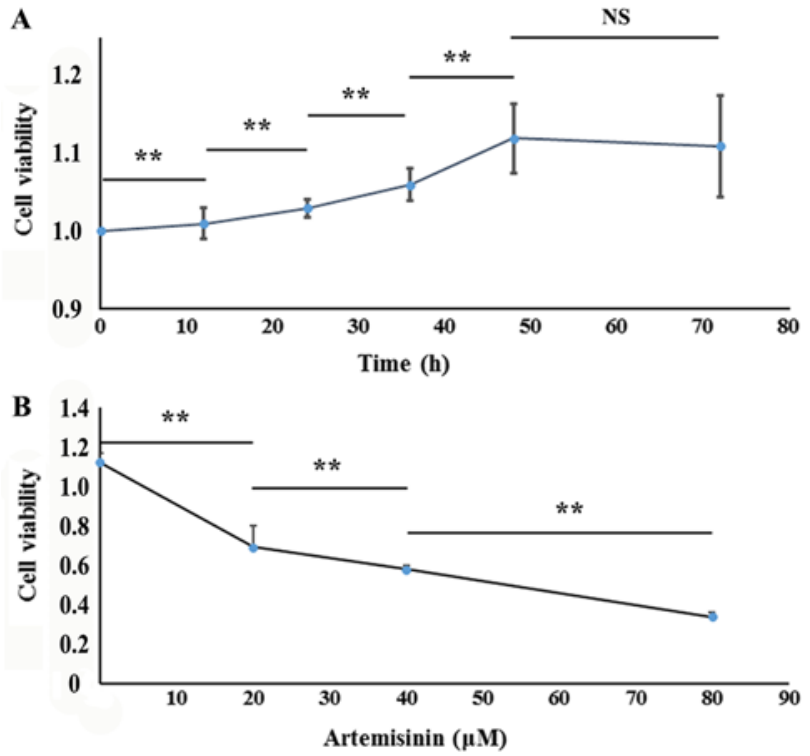

Figure 1. Celecoxib and artemisinin regulate SKOV3 cell viability. (A) Effect of $10 \mu \mathrm{M}$ celecoxib on SKOV3 cell viability (i.e. EMT model) following incubation for 0, 12, 24, 36, 48 and $72 \mathrm{~h}$. (B) Effects of artemisinin $(20,40$ and $80 \mu \mathrm{M})$ on the viability of MET model cells at $48 \mathrm{~h} .{ }^{* *} \mathrm{P}<0.01$. NS, no significance.

Statistical analysis. Data are presented as the mean \pm standard deviation. SPSS software (version 16.0 for Windows; SPSS, Inc.) was used for statistical analysis. Data were analyzed with one-way analysis of variance and Student's t-test. The least significant difference test was used as a post hoc test for comparison between multiple groups. $\mathrm{P}<0.05$ was considered to indicate a statistically significant difference.

\section{Results}

SKOV3 cell proliferation was promoted by celecoxib and suppressed by artemisinin. To assess the effect of celecoxib and artemisinin on SKOV3 cell proliferation, cell viability was tested using CCK-8. SKOV3 cells were incubated with $10 \mu \mathrm{M}$ celecoxib for $0,12,24,36,48$ and $72 \mathrm{~h}$, which resulted in cell viability values of $1,1.01 \pm 0.02,1.03 \pm 0.01,1.06 \pm 0.02$, $1.12 \pm 0.05$, and $1.11 \pm 0.07$, respectively (Fig. 1A). SKOV3 cells incubated with celecoxib for $48 \mathrm{~h}$ exhibited the highest viability; thus, the $48 \mathrm{~h}$ incubation period was chosen as optimal for the EMT cell model for subsequent experiments. The cell viability values of the EMT and MET cell models (20,40 and $80 \mu \mathrm{M}$ artemisinin; $48 \mathrm{~h}$ ) were $1.12 \pm 0.05,0.69 \pm 0.11$, $0.58 \pm 0.39,0.34 \pm 0.58$, respectively $(\mathrm{P}<0.01$; Fig. $1 \mathrm{~B})$. These results indicated that celecoxib promoted cell viability in a time-dependent manner, whereas artemisinin inhibited cell viability in a dose-dependent manner.

SKOV3 cell migratory ability was promoted by celecoxib and inhibited by artemisinin. To evaluate the potential role of celecoxib and artemisinin on the migratory ability of SKOV3 cells, wound healing assay was performed. The scratch-healing rates were $0.25 \pm 0.01$ in the control group and $0.53 \pm 0.02$ following $48-\mathrm{h} 10 \mu \mathrm{M}$ celecoxib treatment, which indicated that cell migration was significantly increased in the EMT model $(\mathrm{P}<0.01$; Fig. 2B). Cell migration was significantly decreased in the MET model $(10 \mu \mathrm{M}$ celecoxib for $48 \mathrm{~h}$ and 20, 40 and $80 \mu \mathrm{M}$ artemisinin for $48 \mathrm{~h}$ ) compared with the EMT model $(\mathrm{P}<0.05)$ with scratch-healing rates of $0.36 \pm 0.01,0.26 \pm 0.01$, and $0.23 \pm 0.01$, respectively (Fig. $2 \mathrm{C}$ ). These results indicated that, in SKOV3 cells, celecoxib may promote migratory ability, whereas artemisinin may inhibit migratory ability.

Celecoxib and artemisinin exhibit opposite effects on E-cadherin and vimentin protein expression in SKOV3 cells. Western blotting (Fig. 3), flow cytometry (Fig. 4) and immunofluorescence (Fig. 5) were used to evaluate whether celecoxib and artemisinin affect E-cadherin and vimentin expression in SKOV3 cells. The results demonstrated that celecoxib reduced the expression of E-cadherin and increased the expression of vimentin (Figs. 3A, 4A and 5A), whereas artemisinin increased the expression of E-cadherin and reduced the expression of vimentin (Figs. 3B, 4B and 5B) in a dose-dependent manner $(\mathrm{P}<0.05)$.

\section{Discussion}

Ovarian cancer the highest mortality rates amongst gynecological malignancies. Metastasis, drug resistance, and recurrence are important factors leading to patient mortality (1). At present, the clinical treatment of ovarian cancer is a multidisciplinary comprehensive process, and cytoreductive surgery combined with platinum-based chemotherapy is the current standard treatment (13-16). However, the ovarian tissue of patients with ovarian cancer gradually increases its tolerance to anticancer drugs, which results in ineffective treatment (17). The selective cyclooxygenase-2 (COX-2) inhibitor and non-steroidal anti-inflammatory drug celecoxib can promote the growth, proliferation and migration of epithelial cancer cells (10). Celecoxib induces EMT and increases the cellular invasiveness in epithelial ovarian cancer cells by activating the PI3K/AKT and mitogen-activated protein kinase kinase/ERK signaling pathways, in which zinc finger E-box binding homeobox 1 is an important regulator $(10,18)$. Liu et al (9) demonstrated that $10 \mu \mathrm{M}$ celecoxib treatment in ovarian cancer A2780 and SKOV3 cells for $48 \mathrm{~h}$ increased invasiveness compared with untreated ovarian cancer cells independently of the COX-2 inhibitory activity of celecoxib; however, the in vitro celecoxib concentration was higher compared with the maximum blood concentrations in human. Celecoxib used in the range of 5-15 $\mu \mathrm{M}$, which is close to physiologically relevant conditions, did not induce physiological damage to ovarian cancer cells (9). Based on these results, $10 \mu \mathrm{M}$ celecoxib was chosen for use in the present study, consistent with other references $(19,20)$. In addition, a clinical study has demonstrated that patients with ovarian cancer with significantly increased COX-2 expression exhibit significantly lower E-cadherin expression (21), which suggests that celecoxib may induce EMT in ovarian cancer cells. In addition to celecoxib, TGF- $\beta 1$ is also a potential factor that affects various biological activities such as proliferation, differentiation, and immune regulation of cancer cells (19). TGF- $\beta 1$ has been identified as the inducing factor of EMT $(19,22)$. However, TGF- $\beta 1$ stably induces EMT for a prolonged period of time ( $\sim 2$ weeks) (23), whereas, celecoxib 
A
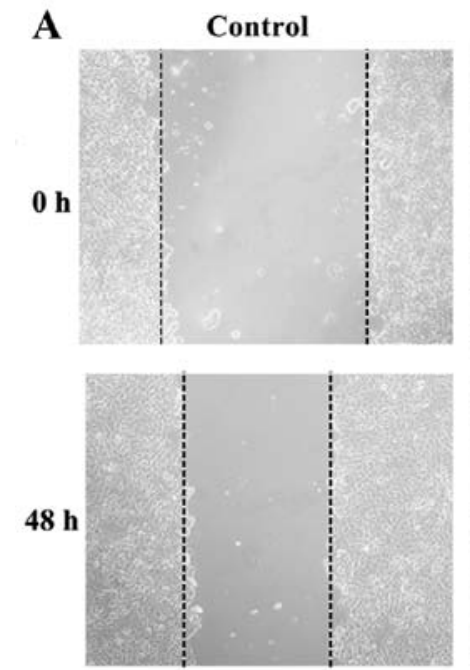

B

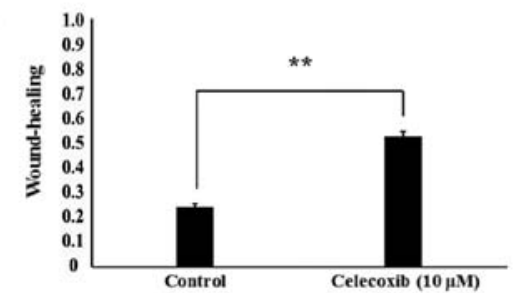

Celecoxib (10 $\mu \mathrm{M})$
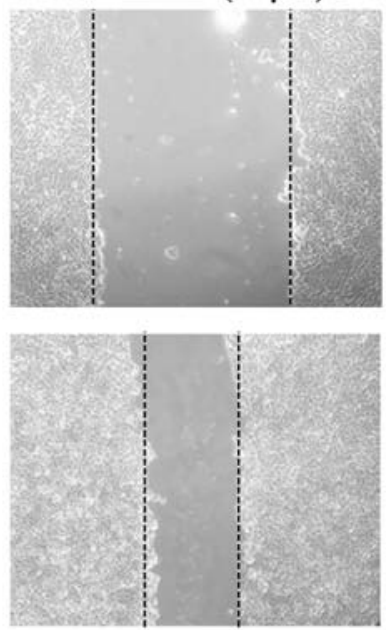

C
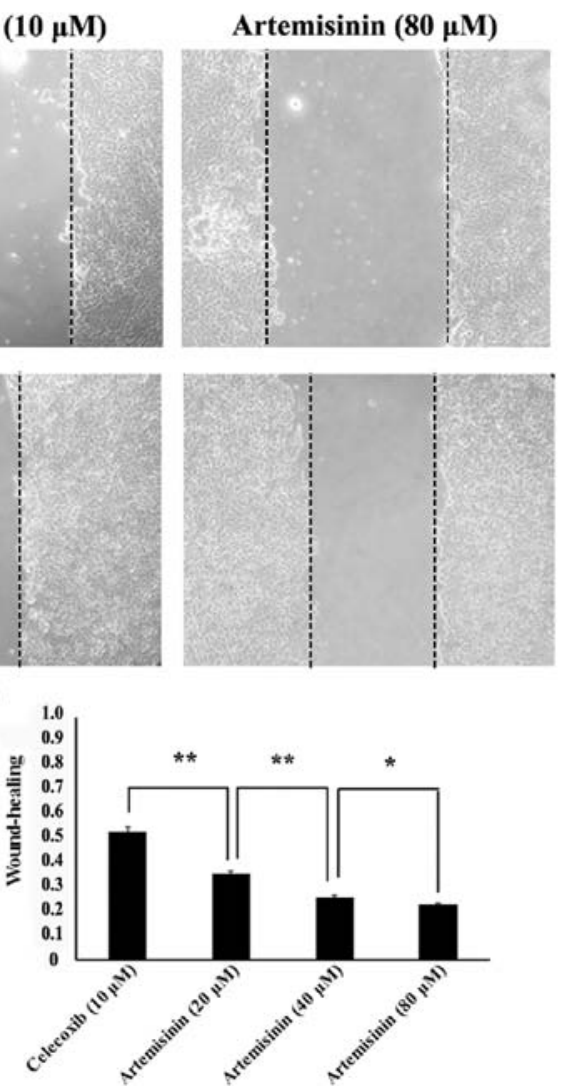

Figure 2. Celecoxib and artemisininregulate the migratory ability of SKOV3 cells. (A) The migratory abilityofcontrols, EMT models (celecoxib $10 \mu \mathrm{M} ; 48 \mathrm{~h}$ ), and mesenchymal-epithelial transition models (artemisinin $80 \mu \mathrm{M} ; 48 \mathrm{~h}$ ). (B) Effects of celecoxib $(10 \mu \mathrm{M} ; 48 \mathrm{~h}$ ) on the migratory ability of cells. (C) Effects of artemisinin $(20,40$ and $80 \mu \mathrm{M} ; 48 \mathrm{~h})$ on the migratory ability of EMT models. ${ }^{* *} \mathrm{P}<0.01$ and ${ }^{*} \mathrm{P}<0.05$. EMT, epithelial-mesenchymal transition.

A Control Celecoxib $(10 \mu \mathrm{M})$
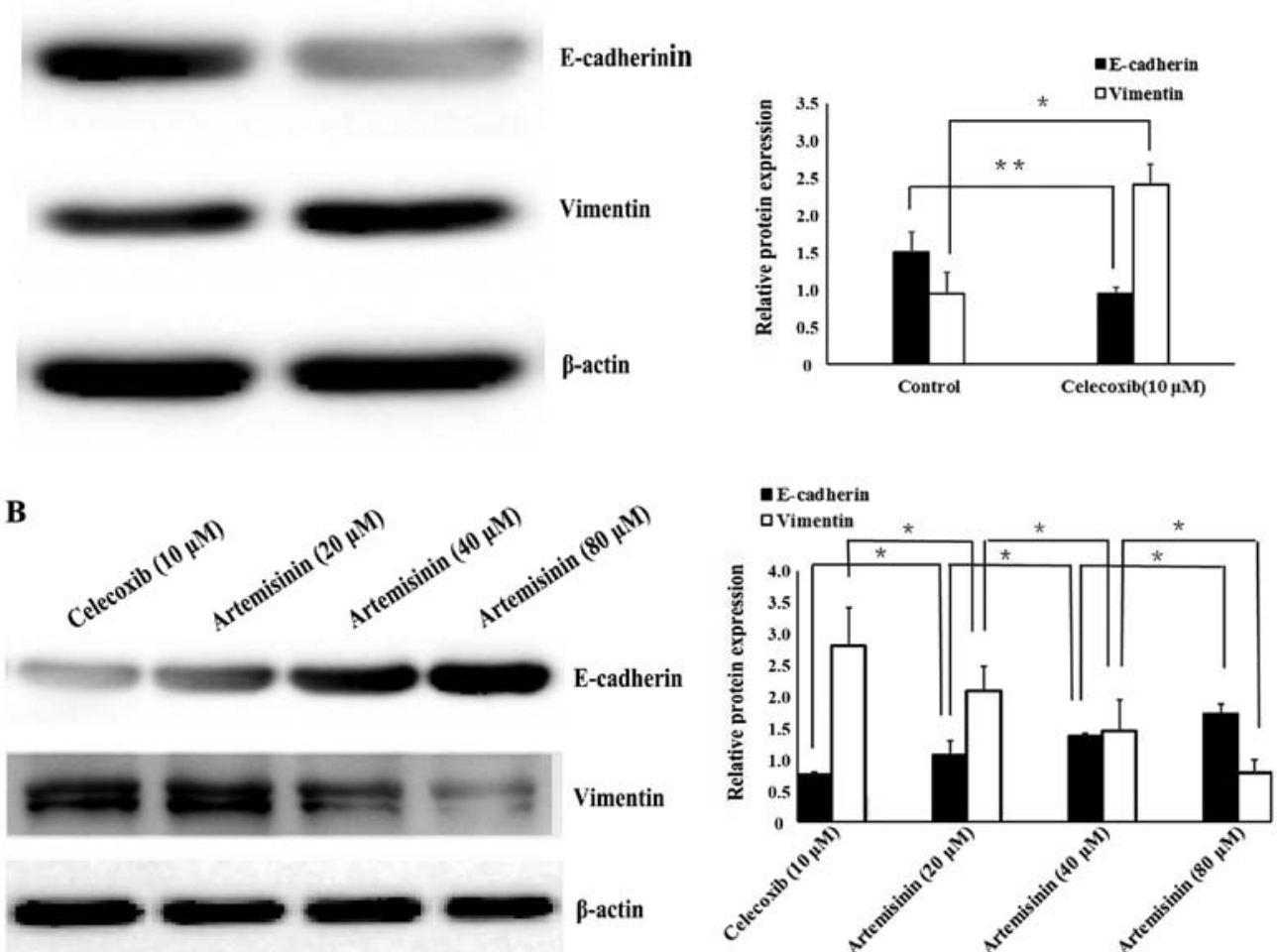

Figure 3. Celecoxib and artemisinin regulate the expression of EMT-related proteins E-cadherin and vimentin in SKOV3 cells. E-cadherin and vimentin protein expression levels were analyzed by western blotting and normalized to $\beta$-actin. (A) Effects of celecoxib (10 $\mu \mathrm{M} ; 48 \mathrm{~h})$ on the expression of E-cadherin and vimentin. (B) Effects of artemisinin $(20,40$ and $80 \mu \mathrm{M} ; 48 \mathrm{~h})$ on the expression of E-cadherin and vimentin in EMT models. " P $<0.01$ and "P<0.05. EMT, epithelial-mesenchymal transition. 

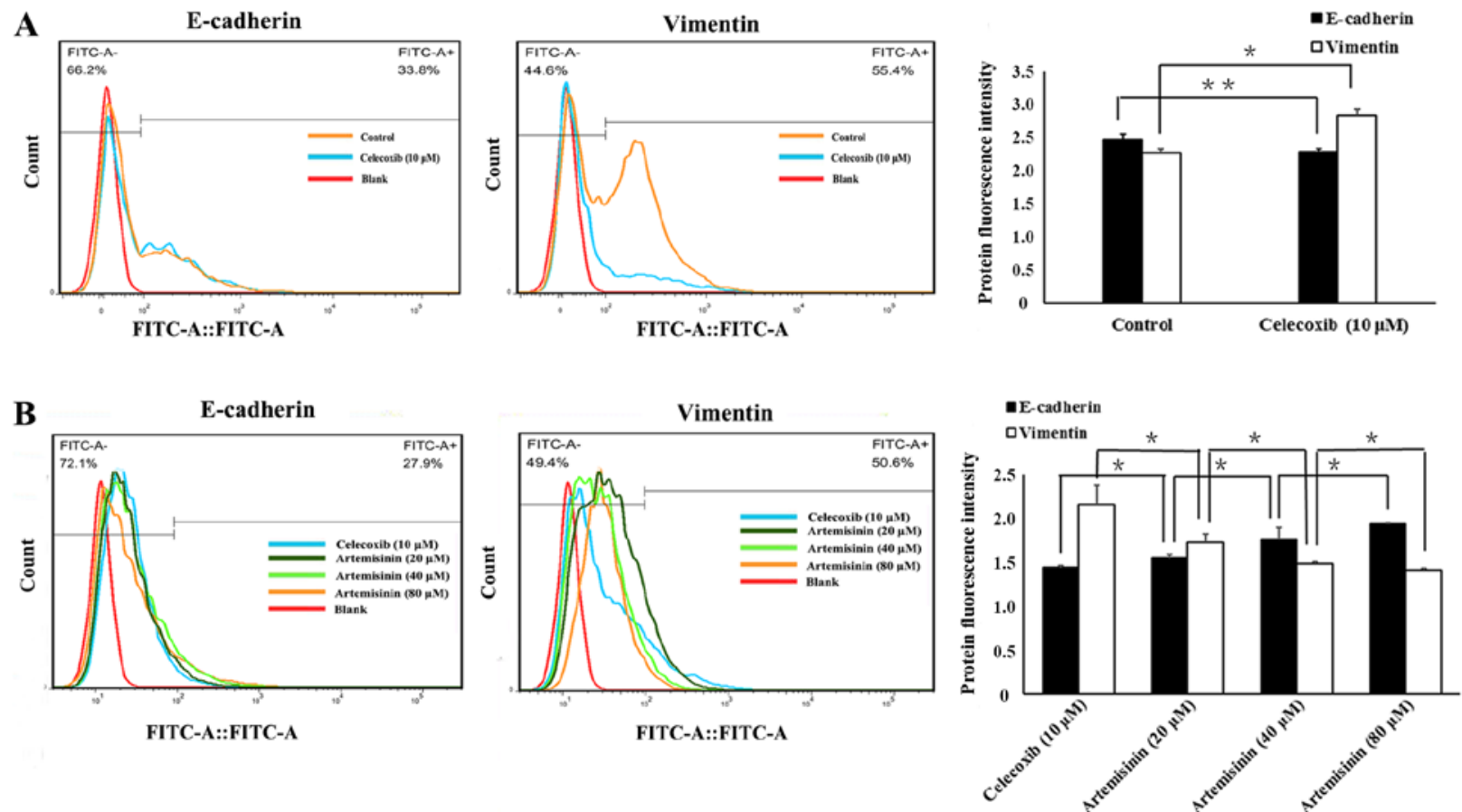

Figure 4. Celecoxib and artemisinin regulate the expression of EMT-related proteins E-cadherin and vimentin in SKOV3 cells. E-cadherin and vimentin protein expression levels were analyzed by flow cytometry. (A) Effects of celecoxib (10 $\mu \mathrm{M} ; 48 \mathrm{~h})$ on the expression of E-cadherin and vimentin. (B) Effects of artemisinin $(20,40$ and $80 \mu \mathrm{M} ; 48 \mathrm{~h})$ on the expression of E-cadherin and vimentin in EMT models. ${ }^{* *} \mathrm{P}<0.01$ and ${ }^{*} \mathrm{P}<0.05$. EMT, epithelial-mesenchymal transition.

A
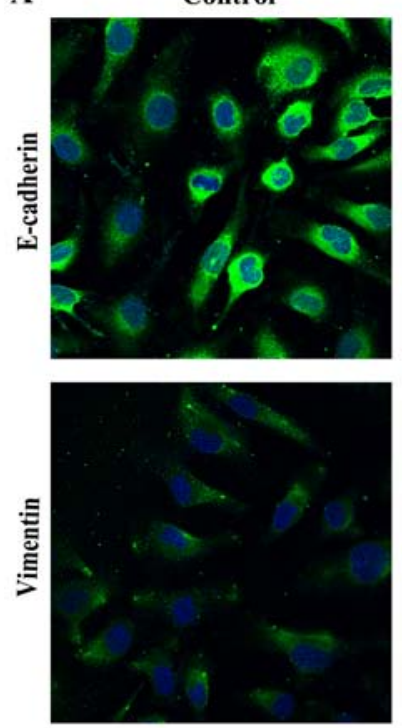

B

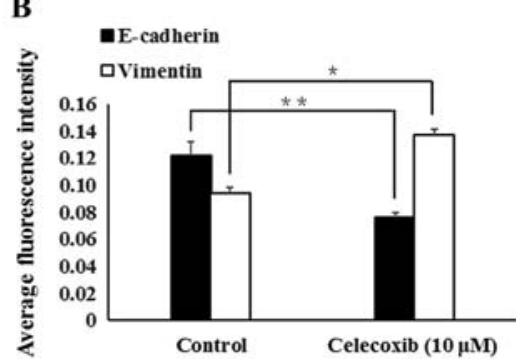

Celecoxib $(10 \mu \mathrm{M})$
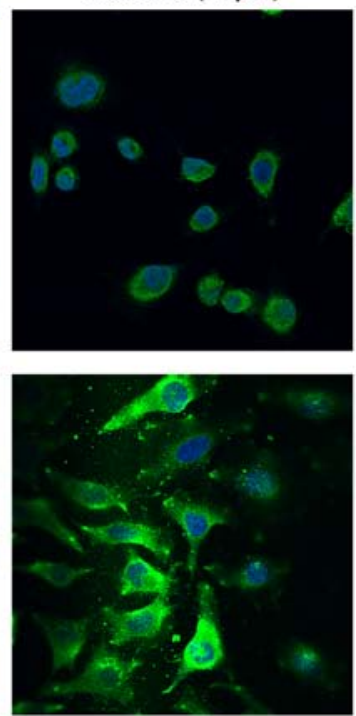

$\operatorname{Artemisinin}(80 \mu \mathrm{M})$
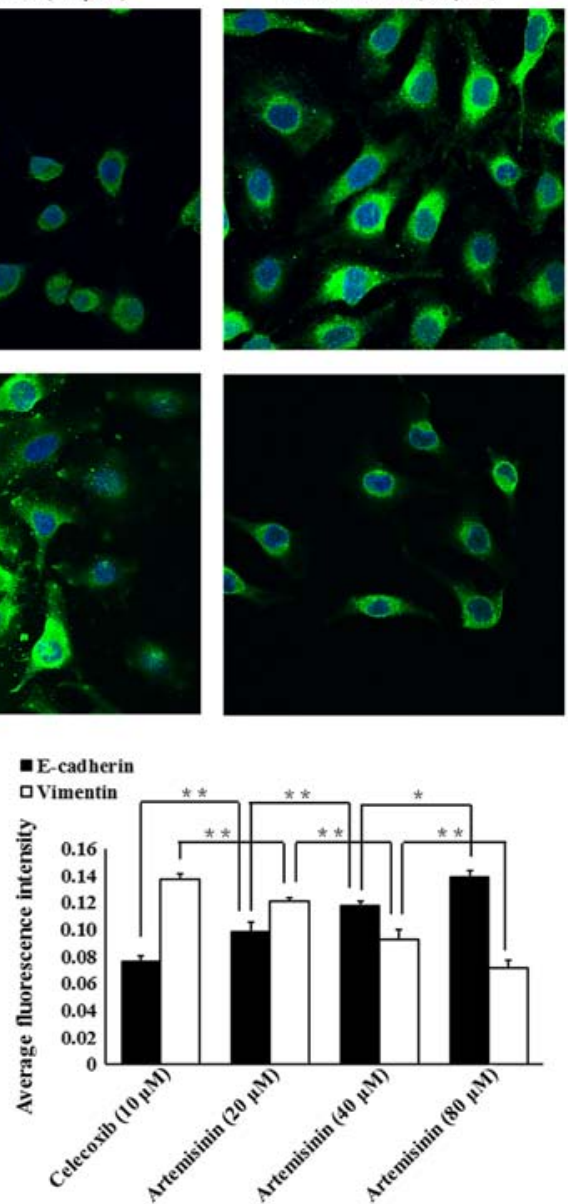

Figure 5. Celecoxib and artemisinin regulate the expression of EMT-related proteins E-cadherin and vimentin in SKOV3 cells. E-cadherin and vimentin protein expression levels were analyzed by immunofluorescence. (A) Effects of celecoxib $(10 \mu \mathrm{M} ; 48 \mathrm{~h})$ on the expression of E-cadherin and vimentin. (B) Effects of artemisinin $(20,40$ and $80 \mu \mathrm{M} ; 48 \mathrm{~h})$ on the expression of E-cadherin and vimentin in EMT models. ${ }^{* *} \mathrm{P}<0.01$ and ${ }^{*} \mathrm{P}<0.05$. EMT, epithelial-mesenchymal transition. 
induces EMT for only $48 \mathrm{~h}$ (19). Artemisinin is an antimalarial drug that also exhibits anticancer activity by inhibiting the proliferation, blocking the cell cycle and promoting apoptosis in cancer cells (24). One study has demonstrated that artemisinin and its derivatives have inhibitory effects on 68 different solid tumors and 24 blood-derived malignant tumors (25). Consistent with these results, the present study demonstrated that the EMT cell model exhibited increased cell proliferation compared with untreated SKOV3 cells, and that artemisinin decreased the cell proliferation.

The invasive and metastatic ability of ovarian cancer cells and drug resistance are associated with EMT (26-29). EMT is a common pathological feature of gastric, colorectal and lung cancer, as well as other malignant tumors (30). EMT affects the morphology of tumor cells, which exhibit pleomorphism, numerous pseudopods, loss of cell polarity and enlarged or multiple nuclei; such morphological features contribute to cell invasion and migration (31). The expression of certain proteins in tumor cells changes during the process of EMT; E-cadherin is a molecular marker of epithelial cells that is localized at the cell membrane, where its extracellular fragments form dimers with adjacent cells, and its intracellular fragments form complexes with related proteins to form an adhesion junction between tumor cells $(32,33)$. Vimentin is marker protein expressed in interstitial cells that reduces adhesion between tumor cells, and increases migration and invasiveness $(32,33)$. In the present study, EMT models exhibited increased vimentin expression and decreased E-cadherin expression, whereas artemisinin reduced vimentin expression and increased E-cadherin expression in a dose-dependent manner. In addition, previous studies have demonstrated that the artemisinin derivative, artesunate, upregulates the expression of genes that inhibit invasion and migration of tumor cells and can, thus, inhibit the invasion and metastasis of renal cancer $(34,35)$. The present study used the wound healing assay to analyze the migration of EMT and MET models and demonstrated that the scratch healing rate of the EMT model was higher compared with control cells or the MET model. These results suggested that artemisinin may reverse and inhibit the EMT process of ovarian cancer cells in a dose-dependent manner.

As a proprietary Chinese medicine, artemisinin is abundant and inexpensive and exhibits low toxicity and high efficiency. Artemisinin not only inhibits the proliferation of cancer cells, but also reverses EMT of tumor cells, blocking their activity (11). Although a number of studies on the antitumor effect of artesunate with scorpion toxin or camptothecin, and other chemotherapeutic drugs have been published, these treatments have only been applied in vitro or in animals and, thus, its clinical value remains to be further explored $(36,37)$. At present, only a small number of studies have investigated the mechanisms of MET. Jeong et al (34) demonstrated that artesunate effectively inhibits the invasion and metastasis of renal cell carcinoma in vivo and in vitro, and downregulates focal adhesion kinase, epidermal growth factor receptor and proto-oncogene c-Met; the sarcoma gene Src is also involved in these processes. In embryonal rhabdomyosarcoma, artesunate effectively inhibits the migration and invasion of tumor cells by upregulating the expression of the cell adhesion molecules neural cell adhesion molecule 1 and integrin $\beta 1$ (35).
Artesunate significantly inhibits the migratory and invasive abilities of esophageal squamous cell carcinoma KYSE-150 cells (38). Artesunate can increase the adhesion of tumor cells and the roughness of the cell membrane, as well as reduce the elasticity of the cell membrane (38). In addition, artesunate inhibits the migration of ovarian cancer cells in vitro by inhibiting the TGF- $\beta$ /WNT signaling pathway (39). In vivo and in vitro experiments in HepG2 and SMMC-7721 cells have revealed that artemisinin significantly inhibits tumor invasion and metastasis through a mechanism associated with upregulation of E-cadherin and tissue inhibitor of metallopeptidase 2 expression and downregulation of metallopeptidase (MMP) 2 expression (40). Dihydroartemisinin inhibited the metastasis of human ovarian cancer HO8910PM cells by downregulating the expression of MMP2 and MMP9, and inhibited EMT induced by platinum-based drugs via the AKT/Snail signaling pathway $(41,42)$.

The present study has established a basis for further investigation of the molecular mechanism of artemisinin in relation to EMT. The possibility that the reversal of EMT during ovarian cancer (i.e. MET) may delay the occurrence of multidrug resistance or even reverse drug resistance may be of great clinical significance in the future.

\section{Acknowledgements}

Not applicable.

\section{Funding}

The present study was supported by grants from the National Natural Science Foundation of China (grant no. 21707002), the Anhui Provincial Natural Science Research General Project (grant no. KJ2015B096by) and the Graduate School of Innovation, Bengbu Medical College (grant no. Byycx1751).

\section{Availability of data and materials}

The datasets used and/or analyzed during the current study are available from the corresponding author on reasonable request.

\section{Authors' contributions}

WL and LM conceived and planned the study. WL, JL and XQ performed the experiments. HW and WL participated in the model establishment. XL, YL and $\mathrm{HZ}$ analyzed the data. All authors read and approved the manuscript and agreed to be accountable for all aspects of the research in ensuring that the accuracy or integrity of any part of the work are appropriately investigated and resolved.

\section{Ethics approval and consent to participate}

All experiments were performed in accordance with a protocol approved by the Use Committee of Bengbu Medical College.

\section{Patient consent for publication}

Not applicable. 


\section{Competing interests}

The authors declare that they have no competing interests.

\section{References}

1. Sureechatchaiyan P, Hamacher A, Brockmann N, Stork B and Kassack MU: Adenosine enhances cisplatin sensitivity in human ovarian cancer cells. Purinergic Signal 14: 395-408, 2018.

2. Chen W, Zheng R, Zhang S, Zeng H, Zuo T, Xia C, Yang Z and He J: Cancer incidence and mortality in China in 2013: An analysis based on urbanization level. Chin J Cancer Res 29: 1-10, 2017.

3. Siegel RL, Miller KD and Jemal A: Cancer statistics, 2018. CA Cancer J Clin 68: 7-30, 2018.

4. Li J, Shao W and Feng H: MiR-542-3p, a microRNA targeting CDK14, suppresses cell proliferation, invasiveness, and tumorigenesis of epithelial ovarian cancer. Biomed Pharmacother 110 850-856, 2018.

5. Polyak K and Weinberg RA: Transitions between epithelial and mesenchymal states: Acquisition of malignant and stem cell traits. Nat Rev Cancer 9: 265-273, 2009.

6. Thiery JP, Acloque H, Huang RY and Nieto MA: Epithelial-mesenchymal transitions in development and disease. Cell 139: 871-890, 2009.

7. Lu DH, Yang J, Gao LK, Min J, Tang JM, Hu M, Li Y, Li ST, Chen J and Hong L: Lysine demethylase 2A promotes the progression of ovarian cancer by regulating the PI3K pathway and reversing epithelial-mesenchymal transition. Oncol Rep 41: 917-927, 2019.

8. Dong J, Jiang D, Wang Z, Wu G, Miao L and Huang L: Intra-articular delivery of liposomal celecoxib-hyaluronate combination for the treatment of osteoarthritis in rabbit model. Int J Pharm 441: 285-290, 2013.

9. Liu R, Zheng J, Li C, Pang Y, Zheng Q, Xu X and Liu P: Celecoxib induces epithelial-mesenchymal transition in epithelial ovarian cancer cells via regulating ZEB1 expression. Arch Gynecol Obstet 291: 1361-1369, 2015.

10. Wang ZL, Fan ZQ, Jiang HD and Qu JM: Selective Cox-2 inhibitor celecoxib induces epithelial-mesenchymal transition in human lung cancer cells via activating MEK-ERK signaling. Carcinogenesis 34: 638-646, 2013.

11. Wong YK, Xu C, Kalesh KA, He Y, Lin Q, Wong WSF, Shen HM and Wang J: Artemisinin as an anticancer drug: Recent advances in target profiling and mechanisms of action. Med Res Rev 37: 1492-1517, 2017

12. Zhang CJ, Wang J, Zhang J, Lee YM, Feng G, Lim TK, Shen HM, Lin Q and Liu B: Mechanism-guided design and synthesis of a mitochondria-targeting artemisinin analogue with enhanced anticancer activity. Angew Chem Int Ed Engl 55: 13770-13774, 2016.

13. Zhang X, Chen J, Sun L and Xu Y: SIRT1 deacetylates KLF4 to activate Claudin-5 transcription in ovarian cancer cells. J Cell Biochem 119: 2418-2426, 2018.

14. Kreuzinger C, Gamperl M, Wolf A, Heinze G, Geroldinger A, Lambrechts D, Boeckx B, Smeets D, Horvat R, Aust S, et al: Molecular characterization of 7 new established cell lines from high grade serous ovarian cancer. Cancer Lett 362: 218-228, 2015.

15. Liu MX, Siu MK, Liu SS, Yam JW, Ngan HY and Chan DW: Epigenetic silencing of microRNA-199b-5p is associated with acquired chemoresistance via activation of JAG1-Notch1 signaling in ovarian cancer. Oncotarget 5: 944-958, 2014

16. Bonneau C, Rouzier R, Geyl C, Cortez A, Castela M, Lis R, Daraï $\mathrm{E}$ and Touboul C: Predictive markers of chemoresistance in advanced stages epithelial ovarian carcinoma. Gynecol Oncol 136: 112-120, 2015.

17. Livney YD and Assaraf YG: Rationally designed nanovehicles to overcome cancer chemoresistance. Adv Drug Deliv Rev 65: 1716-1730, 2013

18. Lim BJ, Jung SS, Choi SY and Lee CS: Expression of metastasisassociated molecules in non-small cell lung cancer and their prognostic significance. Mol Med Rep 3: 43-49, 2010.

19. Cha BK, Kim YS, Hwang KE, Cho KH, Oh SH, Kim BR, Jun HY, Yoon KH, Jeong ET and Kim HR: Celecoxib and sulindac inhibit TGF- $\beta 1$-induced epithelial-mesenchymal transition and suppress lung cancer migration and invasion via downregulation of sirtuin 1. Oncotarget 7: 57213-57227, 2016
20. Bocca C, Bozzo F, Cannito S, Parola M and Miglietta A: Celecoxib inactivates epithelial-mesenchymal transition stimulated by hypoxia and/or epidermal growth factor in colon cancer cells. Mol Carcinog 51: 783-795, 2012.

21. Wang YP, Wang QY, Li CH and Li XW: COX-2 inhibition by celecoxib in epithelial ovarian cancer attenuates E-cadherin suppression through reduced Snail nuclear translocation. Chem Biol Interact 292: 24-29, 2018.

22. Li Z, Hou P, Fan D, Dong M, Ma M, Li H, Yao R, Li Y, Wang G, Geng P, et al: The degradation of EZH2 mediated by lncRNA ANCR attenuated the invasion and metastasis of breast cancer. Cell Death Differ 24: 59-71, 2017.

23. Pang MF, Georgoudaki AM, Lambut L, Johansson J, Tabor V, Hagikura K, Jin Y, Jansson M, Alexander JS, Nelson CM, et al: TGF- 31 -induced EMT promotes targeted migration of breast cancer cells through the lymphatic system by the activation of CCR7/CCL21-mediated chemotaxis. Oncogene 35: 748-760, 2016.

24. Li X, Zhou Y, Liu Y, Zhang X, Chen T, Chen K, Ba Q, Li J, Liu $\mathrm{H}$ and Wang $\mathrm{H}$ : Preclinical efficacy and safety assessment of artemisinin-chemotherapeutic agent conjugates for ovarian cancer. EBioMedicine 14: 44-54, 2016.

25. Hooft van Huijsduijnen R, Guy RK, Chibale K, Haynes RK, Peitz I, Kelter G, Phillips MA, Vennerstrom JL, Yuthavong Y and Wells TN: Anticancer properties of distinct antimalarial drug classes. PLoS One 8: e82962, 2013.

26. Fang D, Chen H, Zhu JY, Wang W, Teng Y, Ding HF, Jing Q, Su SB and Huang S: Epithelial-mesenchymal transition of ovarian cancer cells is sustained by Racl through simultaneous activation of MEK1/2 and Src signaling pathways. Oncogene 36: 1546-1558, 2017

27. Lee HM, Hwang KA and Choi KC: Diverse pathways of epithelial mesenchymal transition related with cancer progression and metastasis and potential effects of endocrine disrupting chemicals on epithelial mesenchymal transition process. Mol Cell Endocrinol 457: 103-113, 2017.

28. Xu Y, Wang C, Su J, Xie Q, Ma L, Zeng L, Yu Y, Liu S, Li S, Li Z and Sun L: Tolerance to endoplasmic reticulum stress mediates cisplatin resistance in human ovarian cancer cells by maintaining endoplasmic reticulum and mitochondrial homeostasis. Oncol Rep 34: 3051-3060, 2015.

29. Yang SH, Sharrocks AD and Whitmarsh AJ: MAP kinase signalling cascades and transcriptional regulation. Gene 513: 1-13, 2013.

30. Mak MP, Tong P, Diao L, Cardnell RJ, Gibbons DL, William WN, Skoulidis F, Parra ER, Rodriguez-Canales J, Wistuba II, et al: A Patient-derived, pan-cancer EMT signature identifies global molecular alterations and immune target enrichment following epithelial-to-mesenchymal transition. Clin Cancer Res 22: 609-620, 2016.

31. Xia L, Zhang B, Yan Q and Ruan S: Effects of saponins of patrinia villosa against invasion and metastasis in colorectal cancer cell through NF- $\kappa$ B signaling pathway and EMT. Biochem Biophys Res Commun 503: 2152-2159, 2018.

32. Zhang Y, Huang P, Liu X, Xiang Y, Zhang T, Wu Y, Xu J, Sun Z, Zhen W,Zhang L, et al: Polyphyllin I inhibits growth and invasion of cisplatin-resistant gastric cancer cells by partially inhibiting CIP2A/PP2A/Akt signaling axis. J Pharmacol Sci 137: 305-312, 2018.

33. Po JW, Roohullah A, Lynch D, DeFazio A, Harrison M, Harnett PR, Kennedy C, de Souza P and Becker TM: Improved ovarian cancer EMT-CTC isolation by immunomagnetic targeting of epithelial EpCAM and mesenchymal N-cadherin. J Circ Biomark 7: 1849454418782617, 2018.

34. Jeong DE, Song HJ, Lim S, Lee SJ, Lim JE, Nam DH, Joo KM, Jeong BC, Jeon SS, Choi HY and Lee HW: Repurposing the anti-malarial drug artesunate as a novel therapeutic agent for metastatic renal cell carcinoma due to its attenuation of tumor growth, metastasis, and angiogenesis. Oncotarget 6: 33046-33064, 2015.

35. Beccafico S, Morozzi G, Marchetti MC, Riccardi C, Sidoni A, Donato R and Sorci G: Artesunate induces ROS- and p38 MAPK-mediated apoptosis and counteracts tumor growth in vivo in embryonal rhabdomyosarcoma cells. Carcinogenesis 36: 1071-1083, 2015

36. Zhang L, Chen F, Zhang Z, Chen Y and Wang J: Synthesis and biological evaluation of a novel artesunate-podophyllotoxin conjugate as anticancer agent. Bioorg Med Chem Lett 26: 38-42, 2016.

37. Li Q, Wang W, Liu Y, Lian B, Zhu Q, Yao L and Liu T: The biological characteristics of a novel camptothecin-artesunate conjugate. Bioorg Med Chem Lett 25: 148-152, 2015. 
38. Shi R, Cui H, Bi Y, Huang X, Song B, Cheng C, Zhang L, Liu J, He C, Wang F, et al: Artesunate altered cellular mechanical properties leading to deregulation of cell proliferation and migration in esophageal squamous cell carcinoma. Oncol Lett 9: 2249-2255, 2015.

39. Marchion DC, Xiong Y, Chon HS, Al Sawah E, Bou Zgheib N, Ramirez IJ, Abbasi F, Stickles XB, Judson PL, Hakam A, et al: Gene expression data reveal common pathways that characterize the unifocal nature of ovarian cancer. Am J Obstet Gynecol 209: 576.e1-576.e16, 2013.

40. Weifeng T, Feng S, Xiangji L, Changqing S, Zhiquan Q, Huazhong Z, Peining Y, Yong Y, Mengchao W, Xiaoqing J and Wan-Yee L: Artemisinin inhibits in vitro and in vivo invasion and metastasis of human hepatocellular carcinoma cells. Phytomedicine 18: 158-162, 2011.
41. Wu B, Hu K, Li S, Zhu J, Gu L, Shen H, Hambly BD, Bao S and Di W: Dihydroartiminisin inhibits the growth and metastasis of epithelial ovarian cancer. Oncol Rep 27: 101-108, 2012.

42. Qin Y, Yang G, Li M, Liu HJ, Zhong WL, Yan XQ, Qiao KL, Yang JH, Zhai DH, Yang W, et al: Dihydroartemisinin inhibits EMT induced by platinum-based drugs via Akt-Snail pathway. Oncotarget 8: 103815-103827, 2017.

This work is licensed under a Creative Commons Attribution-NonCommercial-NoDerivatives 4.0 International (CC BY-NC-ND 4.0) License. 